Original Research

\title{
Effects of Polyethylene Microplastics Exposure on Intestinal Flora of Zebrafish
}

\author{
Ying-Hao Xue ${ }^{1,2}$, Zhan-Xiang Sun ${ }^{3 *}$, Zhi-Yu Xu ${ }^{2}$, Liang-Shan Feng ${ }^{3}$, Feng-Yan Zhao ${ }^{3}$, \\ Xin-Li Wen ${ }^{4}$, Tuo Jin ${ }^{2}$ \\ ${ }^{1}$ College of Land and Environment, Shenyang Agricultural University, Shenyang 110866, P.R. China \\ ${ }^{2}$ Rural Energy and Environment Agency, Ministry of Agriculture and Rural Affairs, Beijing 100125, P.R. China \\ ${ }^{3}$ Liaoning Academy of Agricultural Sciences, Shenyang 110161, P.R. China \\ ${ }^{4}$ School of Ecology and Environment, Anhui Normal University, Wuhu 241000, P.R. China
}

Received: 18 January 2021

Accepted: 3 May 2021

\begin{abstract}
Microplastic (MP) is an environmental pollutant, which is toxic to aquatic organisms and may affect their microbial community structure. Here, MP exposure with size-dependent and timedependent effects on gut microbiota of zebrafish were evaluated. High throughput sequencing of the V3-V4 region of the 16S rRNA gene revealed that the core microflora consisted of Fusobacteria, Proteobacteria, Firmicutes, Bacteroidetes, and Actinobacteria. At the phylum level, the relative abundance of Verrucomicrobia, Tenericutes, and Firmicutes significantly decreased in the MP-treated groups compared with the control group, while the abundance of Actinobacteria and Bacteroidetes significantly increased in the MP-treated group. By contrast, the relative abundance of Verrucomicrobia, Chlamydiae, and Chloroflexi significantly increased in the guts of fish in the 10-day group compared with the 1-day and 5-day groups. Besides, there were five specific genera in correlation with MP, including Porphyromonas, Xanthobacter, Campylobacter, IMCC26134 (unclassified Verrucomicrobia), and Lachnoanaerobaculum. Alpha and beta diversity analyses indicated no significant differences in bacterial communities in different treatments. However, LEfSe analysis showed that the gut microbiota composition was different between treatments and control. These results indicate that polystyrene MP can modify the gut microbiota composition; consequently, the health risks of MP to aquatic organisms should not be ignored.
\end{abstract}

Keywords: polyethylene microplastic, 16S rRNA sequencing, gut microbiota, zebrafish

*e-mail: sunzx67@163.com 


\section{Introduction}

Gut microbiota plays an important role in host metabolism, immunity, and homeostasis [1]. A combination of factors can affect the composition of gut microbiota, including the host's genetic background, lifestyle, and feeding habits, as well as selective pressures on the gut environment [2-4]. Furthermore, gut microbiota dynamics are highly sensitive to exogenous stressors. Recent studies have demonstrated that exposure to different kinds of environmental pollutants, including antibiotics, nanomaterials, pesticides, heavy metals, and persistent organic pollutants, can effectively induce gut microbiota dysbiosis in different experimental models [5-7].

Microplastic (MP) is a ubiquitous environmental pollutant in the ocean and freshwater ecosystems; many organisms can easily absorb it due to its small size. Microplastic absorption affects physiology, metabolism, and behavior in organisms, and even induces cell death. The ingestion of MP reportedly causes pathological stress and tissue damage in the livers of developing zebrafish (Danio rerio) [8]. Marine fish (Oryzias latipes) reportedly ingest and bioaccumulate the toxic chemical substances sorbed to microplastics, resulting in pathological and oxidative stress along with liver inflammation [9]. Other studies show that MP can alter feeding of Cybister japonicus [10] and swimming behaviors of Carassius auratus [11] during trophic transfer. Recent reports indicate that feeding on polystyrene MP can affect the gut microbiome of fish and induce metabolic disturbance [12]. MP readily adsorbs pollutants in water, and is easily colonized by microorganisms (like bacteria, fungi, protozoa, and algae) to form biofilms (inorganic and organic, or initial conditional membranes), which may accumulate many pathogens and increase the probability of disease [13]. The composition and distribution of biofilms on the surface of the MPs were analyzed using 16S rRNA sequencing [14], and the results indicated that MPs were enriched with certain dominant bacteria such as Vibrionaceae, Rhodobacteraceae, Flavobacteraceae, Microtrichaceae, and Sphingomonadaceae, compared with seawater samples. Among them, Vibrionaceae, Rhodobacteraceae, and Flavobacteraceae are associated with tissue damage in stony corals, and Vibrios are the main pathogens of coral albinism. However, the effects of polyethylene MP exposure on aquatic animal gut microbiota and overall health are not well understood.

Many microbes colonize on the intestine of their hosts and influence host physiology and immunity [15]. In turn, the host controls which species cannot colonize by mounting immune responses [16]. The overall compositional balance of the gut microbial community is important for ensuring balance in the intestinal mucosa and beyond [17]. In some cases of zebrafish, induction of endocytosis depends on microbiota [18], indicating that gut inflammation is influenced by a combination of chemicals and microbiota. Attention to gut microbiota is essential when investigating the toxicity of MP, but the mechanisms underlying the effects of MP on zebrafish gut microbiota remain unclear. We believe that the data acquired in this study provide a theoretical basis for understanding the toxicity of MP to aquatic organisms.

The zebrafish has become a model animal in the field of disease modeling, toxicology evaluation, and drug screening $[19,20]$ because the species is stable, easily bred, has transparent embryos, and can be readily observed. Also, the similarity between zebrafish and human genes is $>80 \%$. Currently, high-throughput sequencing technologies are promising tools for deep exploration of microbial communities [21]. This study was designed (1) to evaluate gut microbial community shift of zebrafish after MP exposure using the 16S rRNA sequencing technology and (2) to explore the correlations of gut microbial community with MP size and exposure time. The results may provide insight into the underlying relationship between changes to intestinal flora and aquatic toxicities.

\section{Materials and Methods}

\section{Ethical Statement}

All protocols were in accordance with the National Institutes of Health Guide for the Care and Use of Laboratory Animals (China).

\section{MP Characterization}

Pristine polyethylene (PE) MP beads with various size ranges $(45-53 \mu \mathrm{m}, 90-106 \mu \mathrm{m}, 250-300 \mu \mathrm{m})$ were purchased from Cospheric Ltd. (California, USA), supplied as $1 \mathrm{~g} / \mathrm{mL}$. Because PE is one of the most used polymers for plastic production worldwide [22], it was an ideal choice for test material in our experiment. The selected PE-MP beads were prepared in 10,000 particles/ $\mathrm{L}$ in deionized water.

\section{Zebrafish Husbandry}

Healthy four-month-old zebrafish $(0.31 \pm 0.02 \mathrm{~g}$ in wet weight, $31.4 \pm 0.6 \mathrm{~mm}$ in body length) were purchased from a fish market (Shenzhen, China). They were cultured in a $332.5-\mathrm{L}(100 \times 95 \times 35 \mathrm{~cm})$ aquarium that was integrated with a filtration system at $25 \pm 1^{\circ} \mathrm{C}$ with a $14 \mathrm{~h} \mathrm{light} / 10 \mathrm{~h}$ dark cycle in culture water (pH: 7.88 \pm 0.004 ; dissolved oxygen: $8.16 \pm 0.04 \mathrm{mg} / \mathrm{L}$; electrical conductivity: $0.248 \pm 0.005 \mathrm{mS} / \mathrm{cm})$. At least 2 weeks before the experiment, zebrafish were fed daily (9:00 am) with commercial food (Inch-gold, China) at $1 \%$ of the average body weight of all specimens, for acclimatization. The feed used in the experiments contained $>45 \%$ crude protein, $>5 \%$ fat, $<3 \%$ fiber, $<12 \%$ ash, $>4 \%$ calcium, $>1.2 \%$ phosphate, and $<10 \%$ moisture, according to the manufacturer's information. The mean $( \pm \mathrm{SD})$ particle size of the feed, which 
included a mix of fishmeal, fish oil, wheat, shrimp meal, defatted soybean, and various vitamins and minerals, was $1.51 \pm 0.17 \mathrm{~mm}$. All zebrafish used in the exposure experiments were monitored to ensure that they were free of parasites and adverse health conditions [23].

\section{Fish Exposure and Sample Collection}

After acclimatization, five zebrafish were randomly selected from the aquarium and transferred into beakers containing $400 \mathrm{~mL}$ of culture water (same as mentioned above), acclimated for $6 \mathrm{~h}$, and then starved for $24 \mathrm{~h}$ before the experiment. Next, MP solution $(10,000$ particles/L) was added to each treatment according to the following protocol:

I) Size group: zebrafish were exposed to MP $(10,000$ particles/L) for 5 days in quantities including no MP (control, CK), 45-53 $\mu \mathrm{m}$ MP (A5), 90-106 $\mu \mathrm{m}$ MP (B5), and 250-300 $\mu \mathrm{m} \mathrm{MP} \mathrm{(C5).}$

II) Time group: 45-53 $\mu \mathrm{m}$ MP (10,000 particles/L) was selected, and three exposure times of $1 \mathrm{~d}$ (A1), $5 \mathrm{~d}$ (A5), and $10 \mathrm{~d}$ (A10) were set.

Three replicate beakers were assigned to each experimental condition. In addition, the beakers were continuously aerated to provide adequate oxygen for the fish and to avoid the agglomeration of microplastic particles. Fish were fed daily. Before feeding, the water was half-replaced, and then half the MPs were added. In all experiments, no fish died during the courseof the exposure.

At the end of the exposure, each group of fish was rinsed with deionized water to remove residual MP particles. Then, all fishes were euthanized by anesthetic overdose $(0.2 \%$ tricaine methane-sulfonate, MS-222) prior to intestinal tract sampling.

DNA Extraction, PCR Amplification, Quantification, and 16S rRNA Gene Sequencing

The genomic DNA (gDNA) in zebrafish intestinal tract was isolated with a DNA isolation kit (Hangzhou Bioer technology, China). DNA integrity and purity were detected using $1 \%$ agargel electrophoresis, and DNA concentration and purity were detected using NanoDrop One. Next, the gDNA was amplified using primers (Forward primer: 5'-ACTCCTACGGGAGGCAGCA-3'; Reverse primer: 5'-GGACTACHVGGGTWTCTAAT-3') to target the $\mathrm{V} 3$ and V4 regions of the bacterial 16S rRNA gene. Amplicon sequencing was completed using the Illumina HiSeq 245-530 platform (Guangdong Magigene Co. Ltd, China). Raw data obtained by sequencing contained the linker and barcode sequences, which were removed before analysis. Reads with overlaps were stitched using USEARCH (v10.0.240) software, and the mosaic data were filtered first using FastP ( $\mathrm{v}$ 0.14.1) to filter out $\mathrm{N}$-containing sequences and low-quality sequences, and then using chimera filtration to obtain valid data (effective tags) for subsequent analysis. The effective tags for all samples were clustered using UPARSE software (http://www.drive5.com/uparse/). The sequences were clustered into operational taxonomic units (OTUs) with 97\% identity, and then the OTUs representing the species sequences were annotated. According to the species annotations, the number of sequences annotated to each classification level (kingdom, phylum, class, order, family, and genus) was counted for each sample. Alpha diversity indices were calculated in QIIME from rarefied samples using the Chaol index for richness and the Shannon and Simpson indices for diversity. Beta diversity was calculated using principal coordinate analysis ( $\mathrm{PCoA})$, based on a Bray-Curtis distance algorithm. The significance of bacterial taxa abundance was evaluated by linear discriminant analysis effect size (LEfSe) [24]. Analysis using the Kruskal-Wallis test yielded an alpha value of $<0.05$, the pairwise Wilcoxon test yielded an alpha value of $<0.05$, and the logarithmic LDA effect score reached 3.0. The sequencing data were deposited in the National Center for Biotechnology Information (NCBI) with the BioProject number of PRJNA662480.

\section{Data Analysis}

All data were evaluated as the mean \pm standard error of the mean. Statistical analyses were performed using one-way analysis of variance and Duncan's test, and the results were analyzed using SPSS version 20.0 software. The level of statistical significance was set at $\mathrm{P}<0.05$.

\section{Results}

\section{Overall Characterization of the Sequencing Data}

The summary information for sequencing of the V3-V4 region of 16S rRNA genes is shown in Table 1. In the size group, 685,751 valid reads from 12 samples with 221 operational taxonomic units (OTUs) were delineated using $97 \%$ as a homology cut-off value. In the time group, 514,978 valid reads from 9 samples with 230 OTUs were delineated.

\section{Effects of MP on the Composition of Gut Microbiota}

The Venn diagram showed that samples shared a large portion of phylum and genus classifications (Fig. 1) after different MP size exposures. At the phylum level, Planctomycetes were specific to CK while Epsilonbacteraeota were specific to MP groups (Fig. 1a). At the genus level, there were five specific phyla in both CK and MP groups (Fig. 1b).

In the time group, 13 phyla were detected after different exposure times. Among them, Dependentiae were specific to A1, Armatimonadetes were specific to A10, and Planctomycetes were specific to A1 and A10; no phyla were specific to A5 (Fig. 1c). At the genus 
Table 1. The number of OTUs and reads of samples.

\begin{tabular}{|c|c|c|c|}
\hline & Sample ID & No. of OTUs & No. of reads \\
\hline \multirow{4}{*}{$\begin{array}{c}\text { Size } \\
\text { group }\end{array}$} & A5 & 187 & 174860 \\
\cline { 2 - 4 } & B5 & 159 & 165266 \\
\cline { 2 - 4 } & C5 & 168 & 183257 \\
\hline \multirow{3}{*}{$\begin{array}{c}\text { Time } \\
\text { group }\end{array}$} & AK & 179 & 162368 \\
\cline { 2 - 4 } & A5 & 177 & 168617 \\
\cline { 2 - 4 } & A10 & 188 & 174648 \\
\hline
\end{tabular}

level, 106 genera were detected and there was one specific genus (Ruminococcus) in A5, six specific genera (Prosthecobacter, Pseudoxanthomonas, Cytophaga, Brevibacillus, Armatimonas, and Gordonia) in A10, and zero specific genera in A1 (Fig. 1d).

a: phylum level



c: phylum level



Next, the phyla and genera shared by all the individuals in the control and treatment groups were used to identify core microbiota. We compared the composition of zebrafish gut microbiota exposed to MPs for different sizes and exposure times. The results showed similar composition among groups (Fig. 2). The identified 15 phyla (relative abundance $\geq 0.01 \%$ ) included Fusobacteria, Proteobacteria, Firmicutes, Bacteroidetes, and Actinobacteria, among others.

We then further compared the differences of specific microflora between different groups. At the phylum level, the relative quantities of Verrucomicrobia and Tenericutes were significantly lower in the group exposed to 45-53 $\mu \mathrm{m}$ MP (A5) than in the CK group, while Actinobacteria quantities were significantly higher in the group exposed to 45-53 $\mu \mathrm{m}$ MP $(\mathrm{P}<0.05$; Fig. 3a). Also, the relative abundance of Bacteroidetes was significantly higher in the group exposed to 90-106 $\mu \mathrm{m}$ MP (B5) than in the CK group, and the

b: genus level

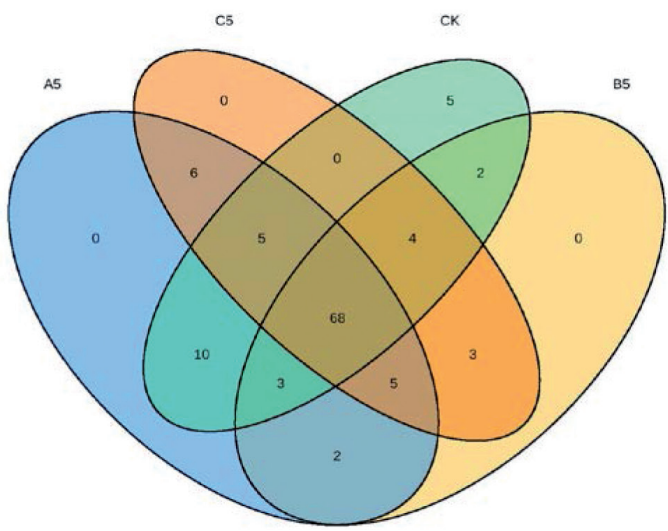

d: genus level

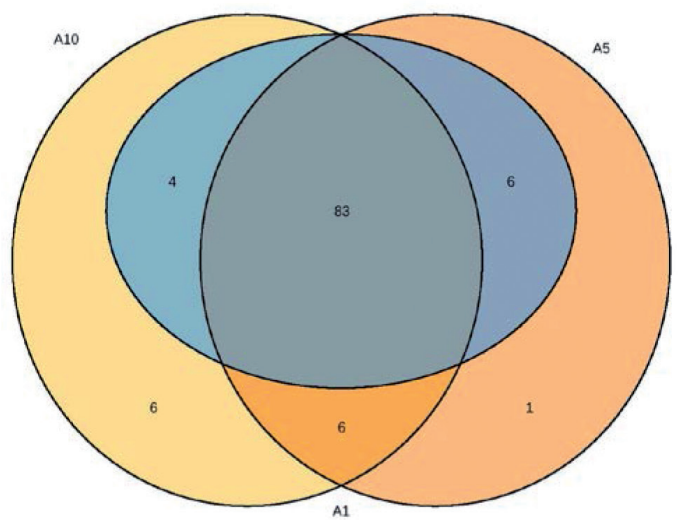

Fig. 1. Venn diagram illustrating overlap of $(a, c)$ phyla and $(b, d)$ genera in gut microbiota of zebrafish treated with $(a, b) 0,45-53 \mu \mathrm{m}$, 90-106 $\mu \mathrm{m}, 250-300 \mu \mathrm{m}$ MP and (c, d) 45-53 $\mu \mathrm{m}$ MP for 1, 5, and 10-days. CK: no MP; A5: 45-53 $\mu \mathrm{m}$ MP-exposed for 5 days; B5: 90-106 $\mu \mathrm{m}$ MP-exposed for 5 days; C5: 250-300 $\mu \mathrm{m}$ MP-exposed for 5 days. A1: 45-53 $\mu \mathrm{m}$ MP-exposed for 1 day; A5: 45-53 $\mu \mathrm{m}$ MPexposed for 5 days; A10: 45-53 $\mu \mathrm{m}$ MP-exposed for 10 days. 
a)

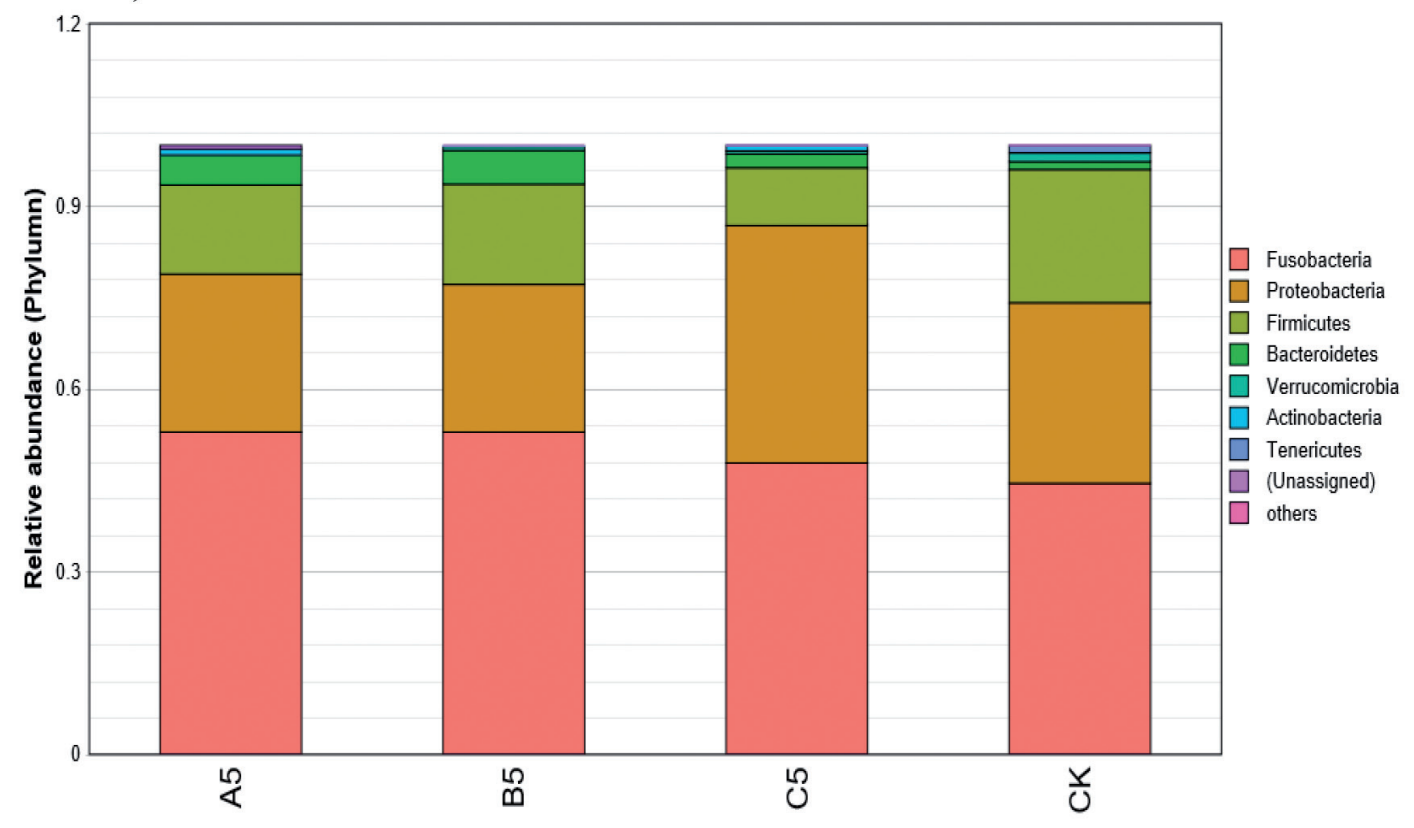

b)

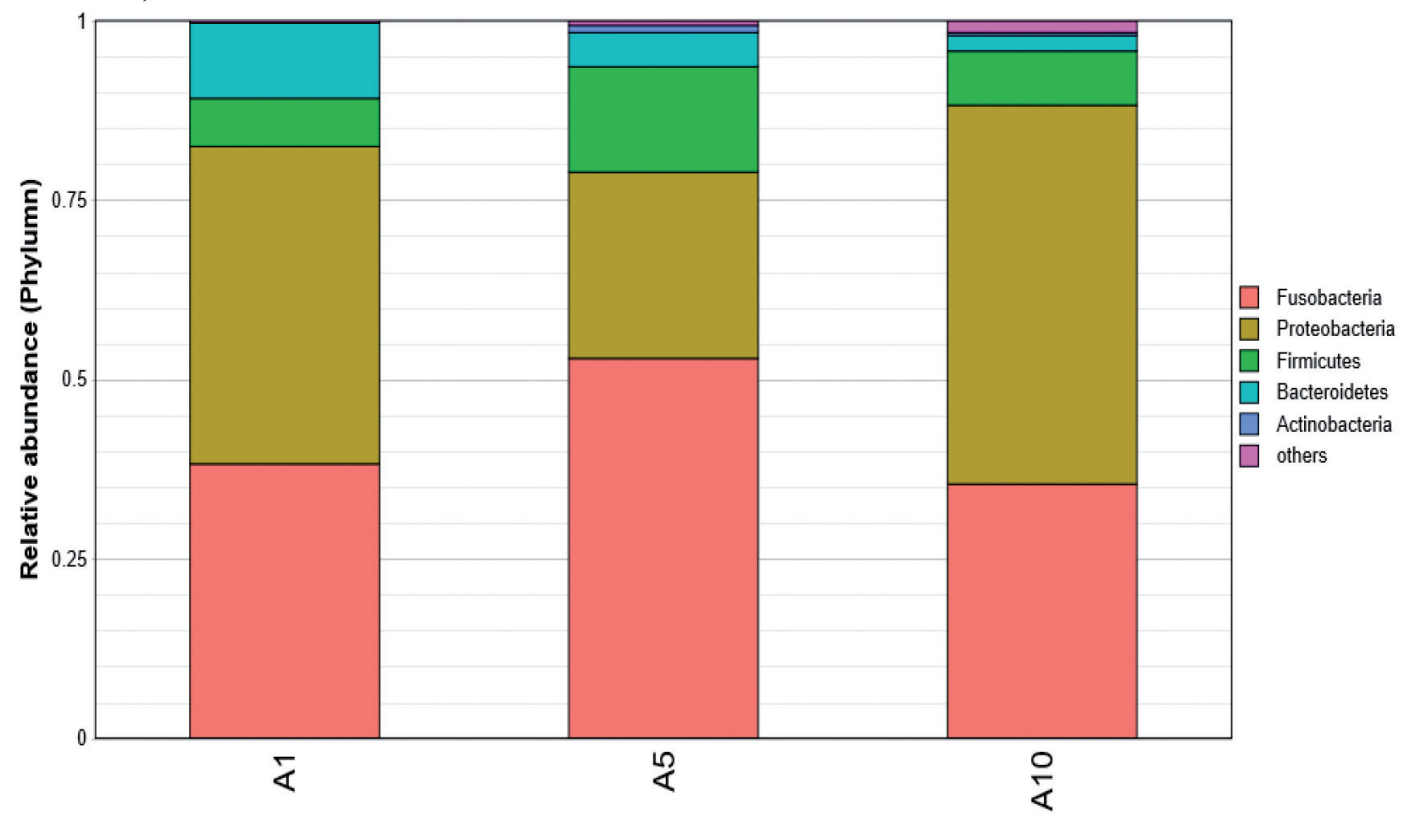

Fig. 2. Change in the gut microbiota composition at the phylum level after a) treated with 0, 45-53 $\mu \mathrm{m}, 90-106 \mu \mathrm{m}, 250-300 \mu \mathrm{m}$ MP; b) treated with 45-53 $\mu \mathrm{m}$ MP for 1, 5 and 10-day (each color represents one bacterial phylum). CK: no MP; A5: 45-53 $\mu \mathrm{m}$ MP-exposed for 5 day; B5: 90-106 $\mu \mathrm{m}$ MP-exposed for 5 day; C5: 250-300 $\mu \mathrm{m}$ MP-exposed for 5 day; A1: $45-53 \mu \mathrm{m}$ MP-exposed for 1 day; A5: 45-53 $\mu \mathrm{m}$ MP-exposed for 5 day; A10: 45-53 $\mu \mathrm{m}$ MP-exposed for 10 day.

relative abundance of Firmicutes was significantly lower in the group exposed to 250-300 $\mu \mathrm{m}$ MP (C5) than in the CK group ( $<<0.05$; Fig. 3a). In addition, the composition of gut microbiota also changed significantly in the gut after 1-day, 5-day, and 10day exposure to 10,000 particles/L of $45-53 \mu \mathrm{m}$ MP. As shown in Fig. 3b), at the phylum level, the relative amounts of Verrucomicrobia, Chlamydiae, and Chloroflexi significantly increased in the guts of fish in the 10-day group compared with the 1-day and 5-day groups $(\mathrm{P}<0.05)$.

At the genus level, the composition of zebrafish gut microbiota also changed after MP exposure (Fig. 3). The relative abundance of Phreatobacter was significantly lower in the group exposed to $90-106 \mu \mathrm{m}$ MP than in the CK group and significantly higher in the guts of fish in the CK and 10-day groups compared with the 1-day group $(\mathrm{P}<0.05)$. In contrast, Shewanella 


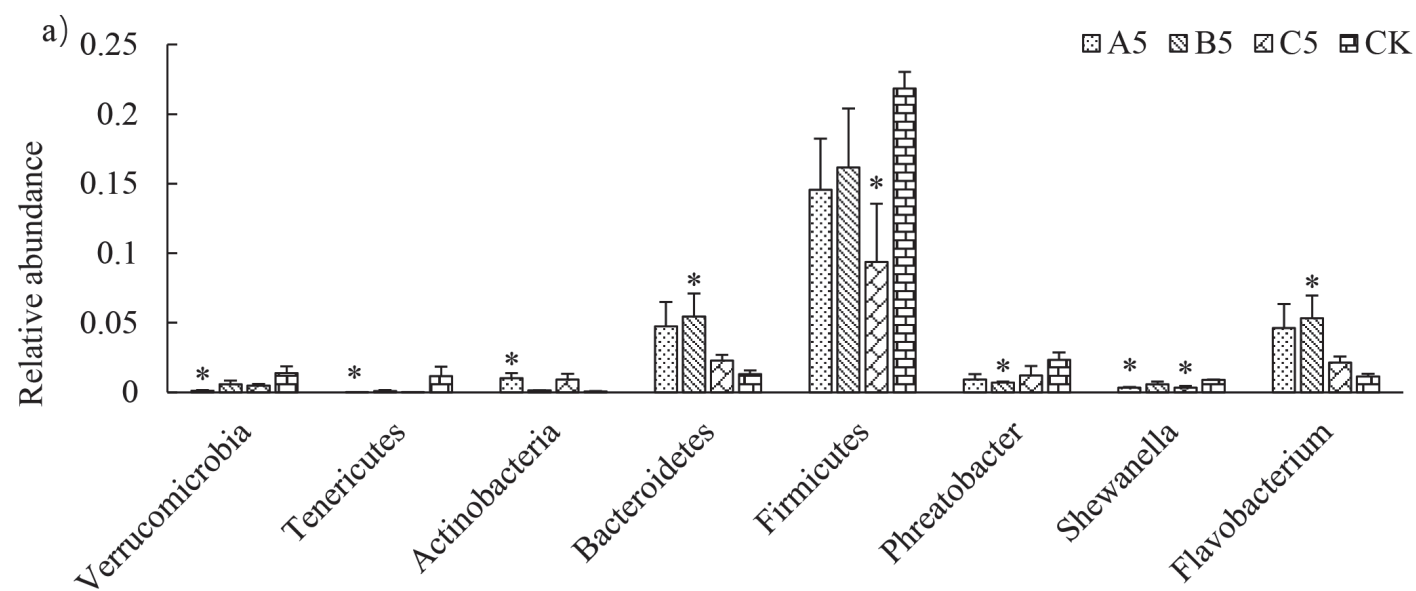

Genus

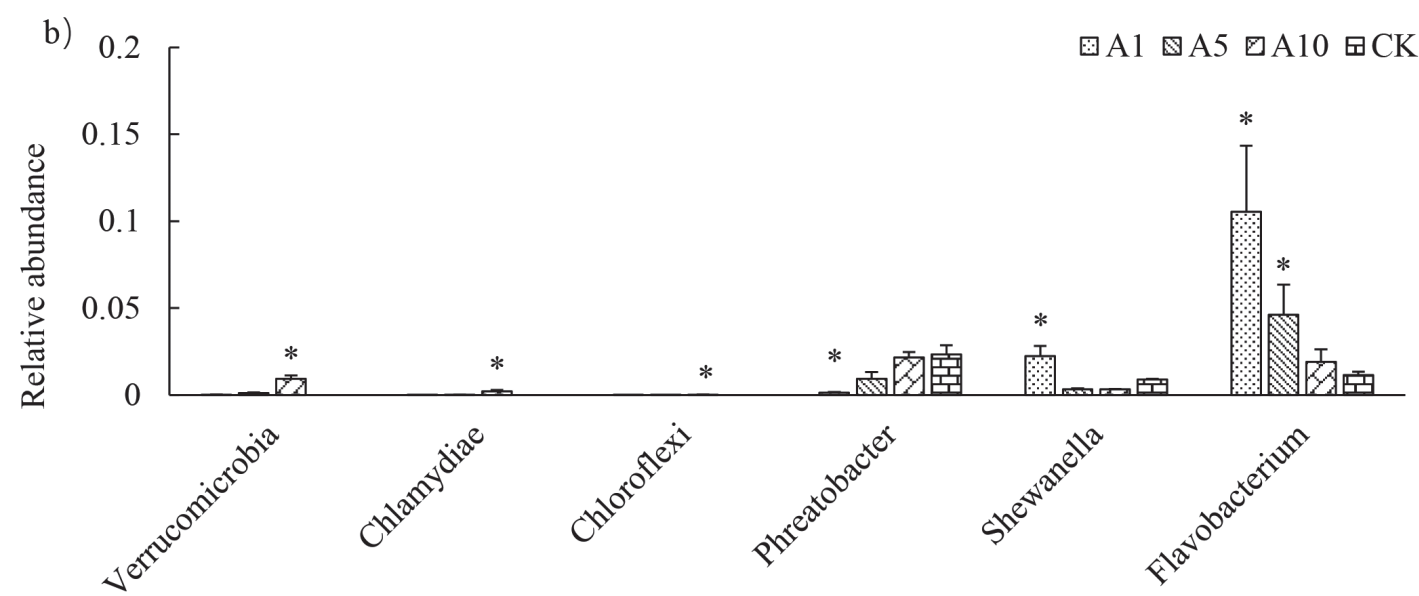

Genus

Fig. 3. Relative abundance of the microbiota at the phylum or genus level in gut microbiota after treatment with a) $0,45-53 \mu \mathrm{m}$, 90-106 $\mu \mathrm{m}, 250-300 \mu \mathrm{m}$ MP for 5 days and b) 45-53 $\mu \mathrm{m}$ MP for 1, 5, and 10-days. CK: no MP; A5: 45-53 $\mu \mathrm{m}$ MP-exposed for 5 days; B5: 90-106 $\mu \mathrm{m}$ MP-exposed for 5 days; C5: 250-300 $\mu \mathrm{m}$ MP-exposed for 5 days. A1: 45-53 $\mu \mathrm{m}$ MP-exposed for 1 day; A5: $45-53 \mu \mathrm{m}$ MP-exposed for 5 days; A10: 45-53 $\mu \mathrm{m}$ MP-exposed for 10 days.

was significantly lower in the groups exposed to 45-53 and 250-300 $\mu \mathrm{m}$ MP than in the CK group, but it was significantly higher in the 1-day group compared with the CK, 5-day, and 10-day groups $(\mathrm{P}<0.05)$. A significant increase of Flavobacterium was observed in the group exposed to 90-106 $\mu \mathrm{m}$ MP compared with the CK group and in the 1-day and 5-day groups compared with the $\mathrm{CK}$ and 10 -day groups $(\mathrm{P}<0.05)$.

\section{Alpha-Diversity Analysis}

The microbial community alpha-diversity was calculated using different diversity indices such as community richness (measured by observed OTUs) (Fig. 4). We did not observe any significant differences in Chaol richness or Shannon and Simpson diversity indices (Figs 4(a-c)) between the CK and MP groups $(\mathrm{P}>0.05)$. The Chaol richness of the community was relatively higher $(\mathrm{P}>0.05)$ in the $\mathrm{A} 5$ and $\mathrm{CK}$ groups compared to the B5 and C5 groups. Simpson diversity (dominance) of the CK group was relatively lower compared to the MP groups $(\mathrm{P}>0.05)$, whereas no significant difference was observed based on Shannon diversity $(\mathrm{P}>0.05)$.

Similarly, alpha-diversity was not significantly different in time groups ( $\mathrm{P}>0.05$; Fig. $4(\mathrm{~d}-\mathrm{f})$ ). The Chao1 richness of the A1 group was similar to that of A5 but different from the A10 group. The average abundance value of the A1 and A10 groups were relatively higher than that of A5 based on Shannon diversity $(\mathrm{P}>0.05)$, but relatively lower than that of A5 based on Simpson diversity $(\mathrm{P}>0.05)$.

\section{Beta-Diversity Analysis}

To detect the extent of the similarities between microbial communities, $\beta$ diversity was measured using Bray-Curtis, and principal coordinate analysis 
a)

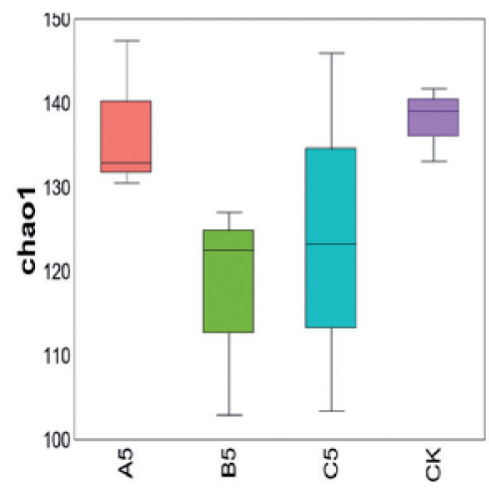

d)

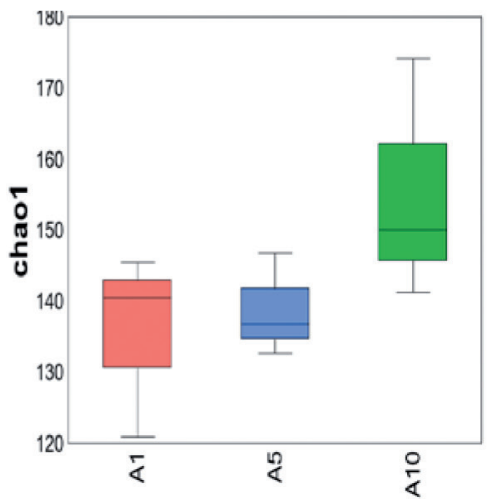

b)

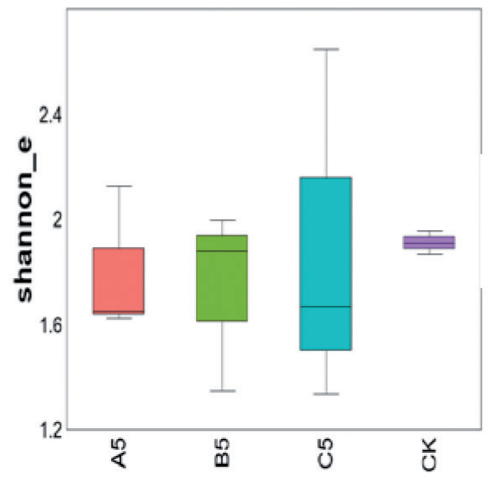

e)

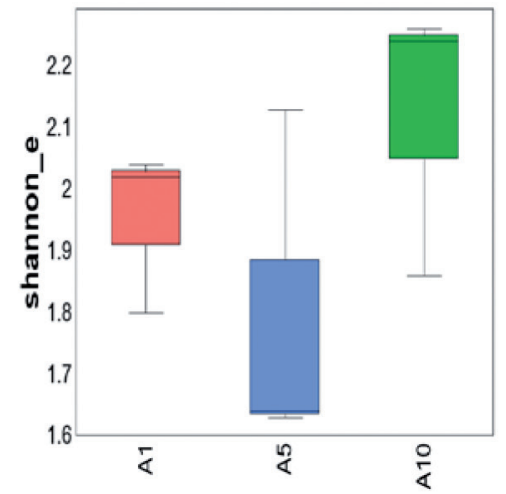

c)

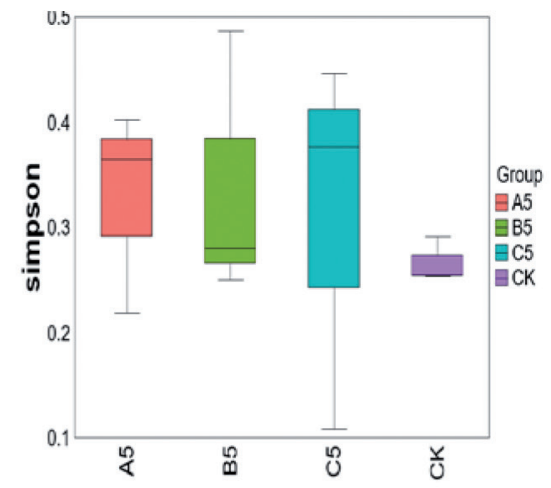

f)



Fig. 4. Alpha diversity indices of the intestinal bacterial communities of zebrafish after treated with (a, b, c) 0, 45-53 $\mu \mathrm{m}, 90-106 \mu \mathrm{m}$, 250-300 $\mu \mathrm{m}$ MP for 5 days and (d, e, f) 45-53 $\mu \mathrm{m}$ MP for 1, 5, 10-day. Chao1 richness (a, d), Shannon diversity (b, e), and Simpson diversity (c, f). CK: no MP; A5: 45-53 $\mu \mathrm{m}$ MP-exposed for 5 days; B5: 90-106 $\mu \mathrm{m}$ MP-exposed for 5 days; C5: 250-300 $\mu \mathrm{m}$ MP-exposed for 5 days. A1: 45-53 $\mu \mathrm{m}$ MP-exposed for 1 day; A5: 45-53 $\mu \mathrm{m}$ MP-exposed for 5 day; A10: 45-53 $\mu \mathrm{m}$ MP-exposed for 10 day.

(PCoA) was performed. Conforming to the above results, the samples clustered together regardless of MP size. However, PCoA results clearly showed that communities from different MP exposure groups were more distant, particularly from those of the CK group (Fig. 5a).

In addition, there were slight differences with regard to different exposure times. The PCoA results showed partially overlapping $95 \%$ confidence interval in the A1 and A5 groups. Results were ambiguous in the A10 group, most likely due to low sample size (Fig. 5b).

\section{Linear Discriminant Analysis Effect Size (LEfSe)}

To identify the specific bacterial taxa associated with MP treatment, the gut microbiota in the controls and the samples treated with MP were compared using LEfSe. A cladogram representation of the microbiota structure and the predominant bacteria is shown in Fig. 6; the greatest differences in taxa are displayed. However, these differences are not comprehensive, in accordance with the analysis above. According to the results of LDA score, Vibrionales showed significantly higher abundance in the $\mathrm{CK}$ group at order level. Vibrionaceae and Chitinibacteraceae were significantly enriched in the CK group at the family level. Vibrio and Paracaedibacter were the dominant genera in the $\mathrm{CK}$ group. In contrast, Actinobacteria and Bacteroidetes were enriched in the treatment group at the phylum level. At the class level, Bacteroidia was dominant in the treatment group. Flavobacteriales and Micrococcales were prevalent at the order level, while Flavobacteriaceae and Microbacteriaceae were prevalent at the family level. Flavobacterium, Chryseobacterium, and Aurantimicrobium were enriched in the treatment group at the genus level.

After exposure to 45-53 $\mu \mathrm{m}$ MP for 1, 5, and 10 days, a difference was found only between A1 and A10 groups (Fig. 7), which is consistent with the findings above. At the genus level, Acidovorax showed significantly higher abundance in the Al group. The abundances of Verrucomicrobia and Verrucomicrobiae significantly increased in the A10 group at phylum and class levels. Verrucomicrobiales, Legionellales, and Rhizobiales were dominant orders in the A10 group at the order level. At the family level, Legionellaceae, Rubritaleaceae, and Terrimicrobiaceae were enriched 
a)

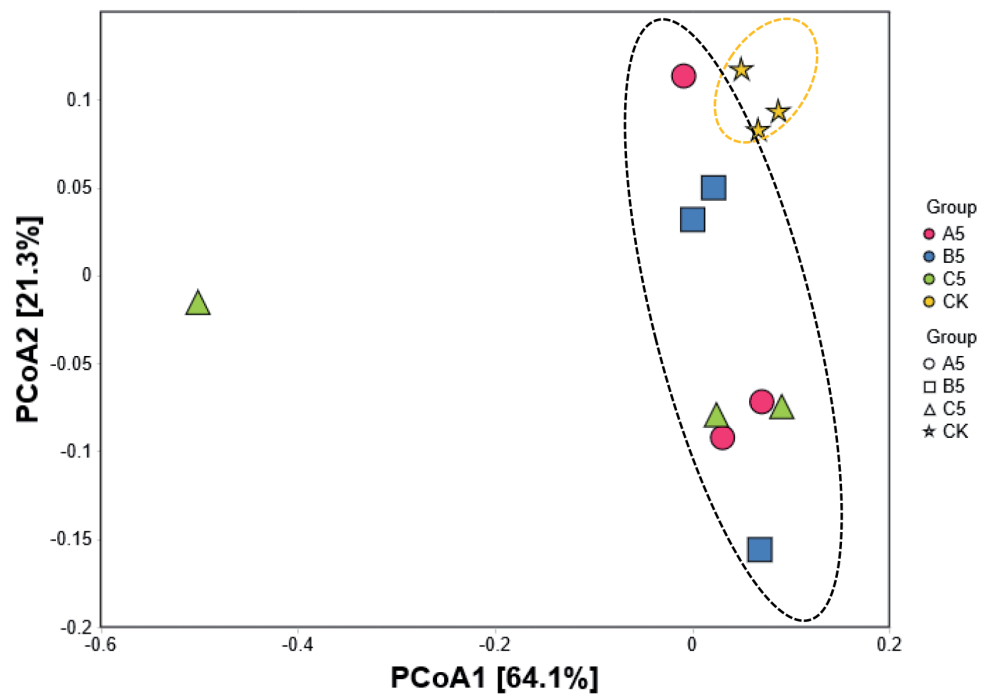

b)

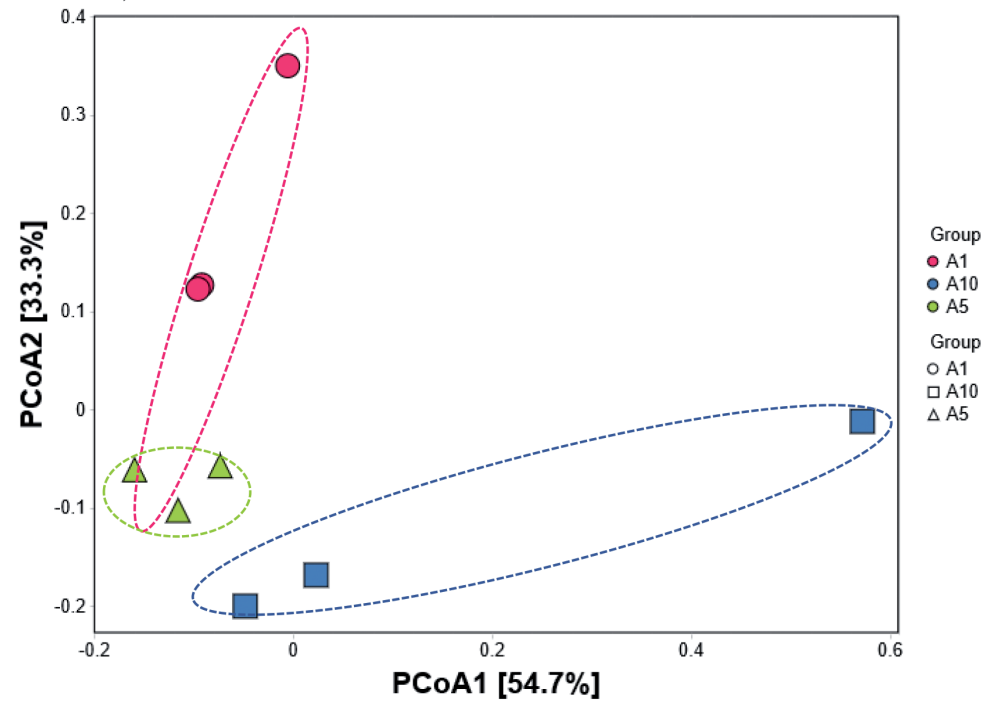

Fig. 5. At the genus level, PCoA based on the bray-curtis distance plotted against the PCoA1 versus PCoA2 axes after a) treated with 0 , 45-53 $\mu \mathrm{m}, 90-106 \mu \mathrm{m}, 250-300 \mu \mathrm{m} \mathrm{MP}$; b) treated with 45-53 $\mu \mathrm{m}$ MP for 1, 5, and 10-days.

in the A10 group. At the genus level, Phreatobacter, Legionella, Luteolibacter, and Terrimicrobium were prevalent in the A10 group.

\section{Discussion}

This study is a characterization of the microbiota of zebrafish treated with MP by $16 \mathrm{~S}$ rRNA sequencing. The data presented, together with previous studies [12], provide a comprehensive view of MP toxicity to gut microbiota of zebrafish. Sequencing of the $16 \mathrm{~S}$ rRNA gene showed that exposure to different MP sizes did not obviously induce the gut microbial community shift. However, gut bacterial diversity had slight variations among treatment groups at different exposure times.
We used PCoA analysis and observed that the gut microbiota composition had shifted by 10 days of MP exposure. Jin et al. [12] studied the effects of polystyrene MP on adult male zebrafish gut microbiota after 14 days of exposure to $100 \mathrm{mg} / \mathrm{L}$ and $1,000 \mathrm{mg} / \mathrm{L} \mathrm{MP}$ at two sizes $(0.5$ and $50 \mu \mathrm{m})$. The study revealed a significant change in the richness and diversity of microbiota in the guts of polystyrene MP-exposed zebrafish. In this study, polyethylene MPs with larger particle sizes were selected on this basis, because previous studies showed that MPs with smaller particle sizes were more harmful to organisms [25, 26]. In addition, we set different exposure times because changes in host microbes are time-dependent [27], and damage to the organism is also related to MP exposure time [28]. We found a core microbiota that was resistant to MP treatment; 
a)

\section{Cladogram}

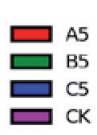

b)

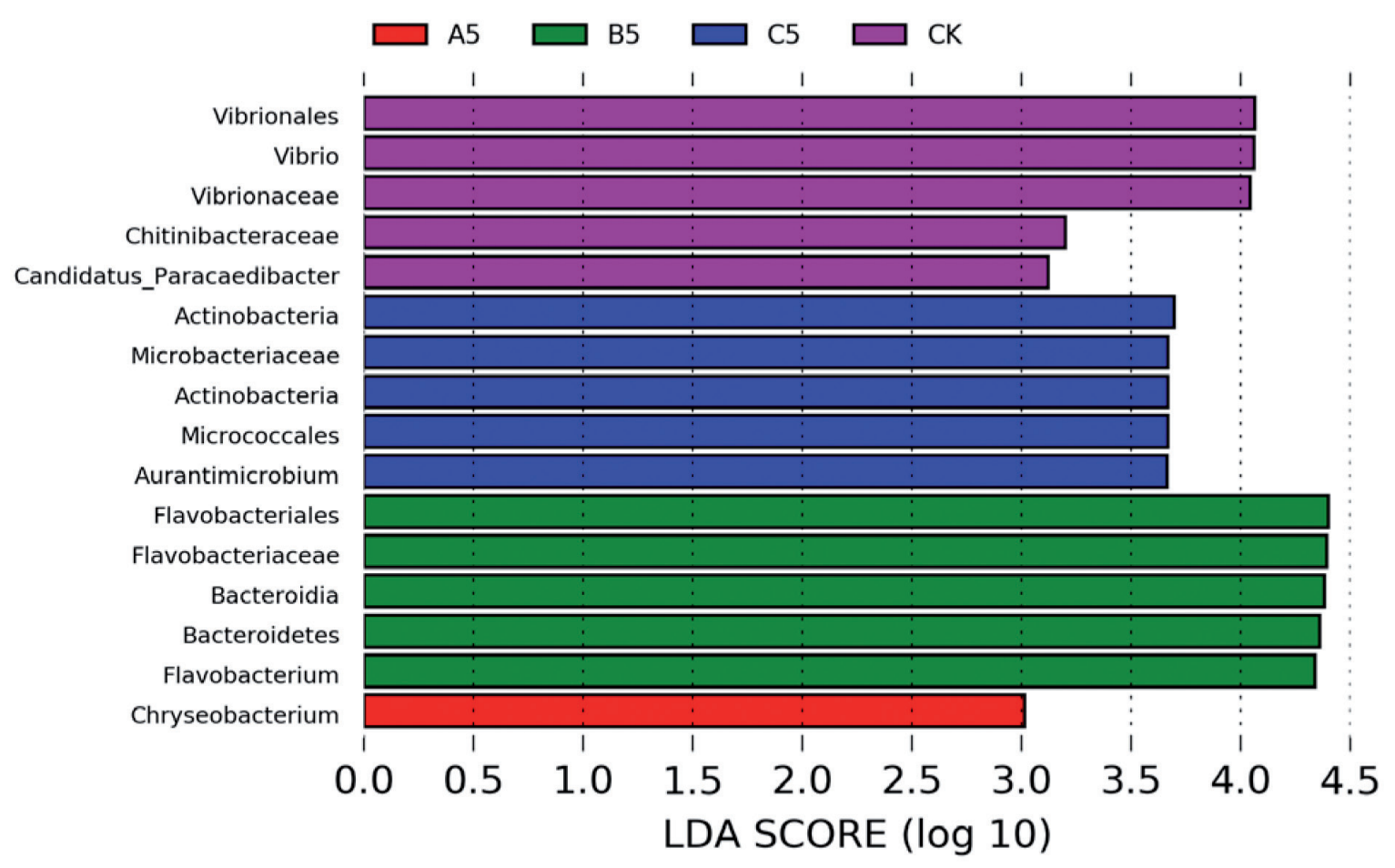

Fig. 6. The most differentially abundant taxons among zebrafish identified by LEfSe after treatment with $0,45-53 \mu \mathrm{m}, 90-106 \mu \mathrm{m}$, 250-300 $\mu \mathrm{m}$ MP. The brightness of each dot is proportional to its effect size a). Only taxa meeting an LDA significant threshold $>3$ are shown b). 
a)

\section{Cladogram}

$\square \mathrm{Al}$

是 a: Pirreatobact

d: Legionellaceae

: Terrimicrobiace

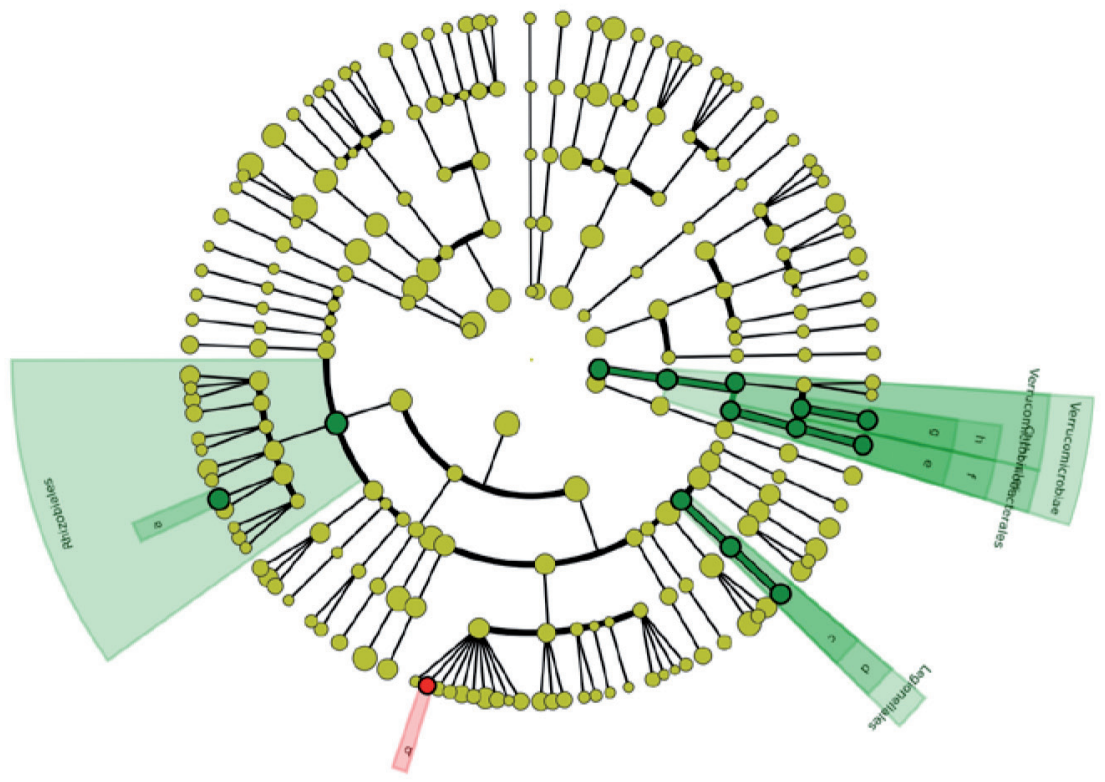

b)

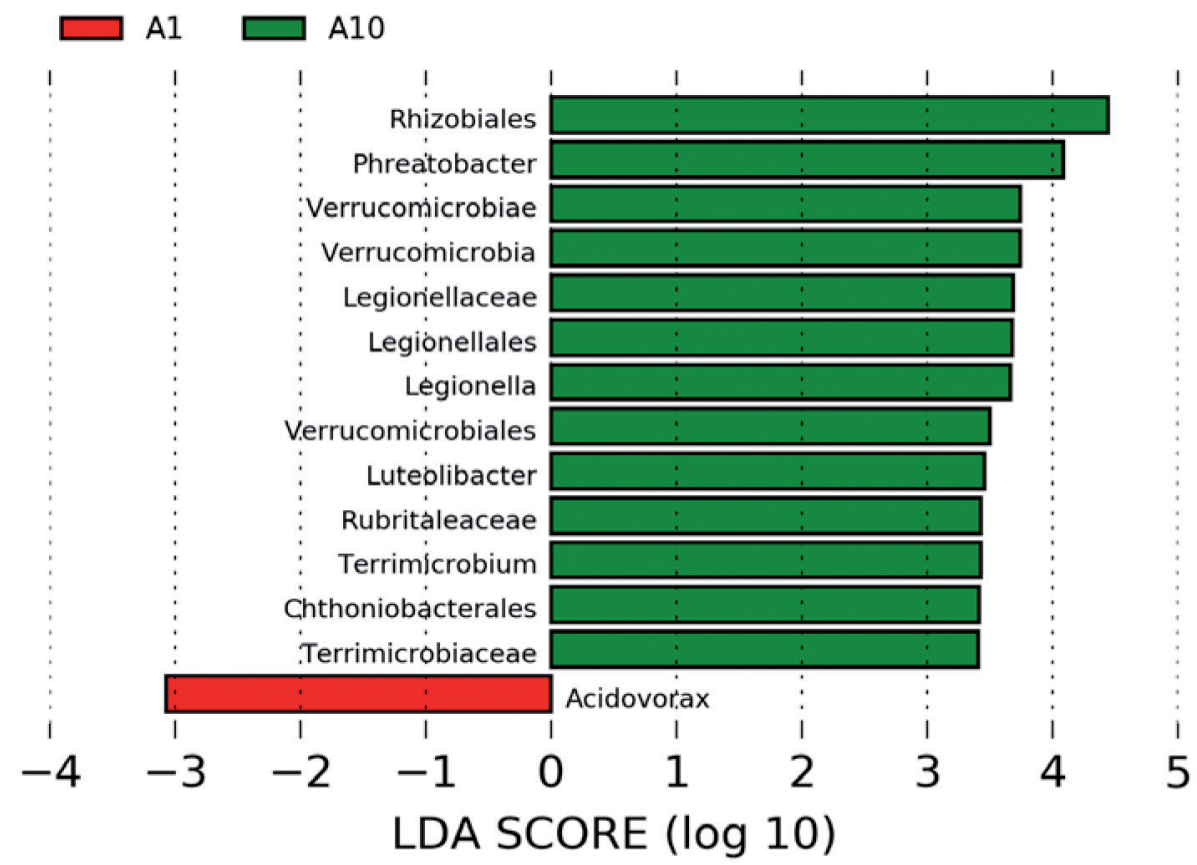

Fig. 7. The most differentially abundant taxons among zebrafish identified by LEfSe after treated with 45-53 $\mu \mathrm{m}$ MP for 1, 5, and 10days. The brightness of each dot is proportional to its effect size a). Only taxa meeting an LDA significant threshold $>3$ are shown b). 
however, due to the scarcity of literature, the effect of MP on the intestinal microbes of zebrafish cannot be determined because of the differences in experimental conditions and operations. Further study of this finding is needed.

Previous studies have shown that phyla Fusobacteria and Proteobacteria dominate the gut microbiota of zebrafish [29, 30]. Similarly, both the control and MP treated zebrafish showed prevalence of phyla Fusobacteria and Proteobacteria in their intestines, with some minor changes in composition. These minor changes did not generate $\alpha$-diversity or $\beta$-diversity differences, which was inconsistent with the results in a previous study that MP could significantly affect the gut microbiota in mice [31]. This contradiction may be due to the differences in species, MP type, and MP size. The absence of these differences led us to explore the possible existence of a core microbiota that is resistant to MP treatment. As expected, the results indicate that both the CK group and the MP treatment groups have a specific phylum with five distinguishing genera. To make our observations more reliable and provide a frame of reference, we compared the microbiota presented here with those identified by Jin et al. [12] who found that at the phylum level, the abundance of Bacteroidetes and Proteobacteria decreased significantly and the abundance of Firmicutes increased significantly after polystyrene MP exposure. In this study, however, the abundance of both Actinobacteria and Bacteroidetes increased significantly, the abundance of Firmicutes decreased significantly, and the abundance of Proteobacteria had no significant change compared with the CK group. The sample size, MP size, and exposure time may contribute to these conflicting outcomes. After treatment at different exposure times, the abundance of core microbiota had no significant change. Possibly, the criteria for core microbiota could be relaxed to include OTUs present in less than $100 \%$ of samples or deeper taxonomic levels [32]. Therefore, further studies with sufficient sample sizes are needed to confirm the core microbiota and determine which taxonomic level is most appropriate for the definition.

Phreatobacter, Shewanella, and Flavobacterium genera, which are closely associated with fish metabolism, disease, and inflammation, exhibited significant differences in both size and time groups. According to these previous studies, Phreatobacter is abundant in waters with low chlorine concentration [32-35]. However, a recent article reported that genus Phreatobacter is prevalent in chlorinated samples, suggesting that its abundance in the planktonic microbial population could result from biofilm, and it could be sensitive to chloramine disinfection and $\mathrm{Cu}^{2+}$ accumulation [36]. In this study, the relative abundance of Phreatobacter was significantly lower in the A1 and B5 groups than in the CK group, possibly due to the continuous circulation of water in the tank.

Genus Shewanella is plentiful in marine and freshwater environments, which is most commonly a secondary or opportunistic pathogen that rarely causes infection. For example, Shewanella algae can produce extracellular virulence factors such as siderophores, exoenzymes, and tetrodotoxin, and may play a role in pathogenesis [37]. In this study, the relative abundance of Shewanella was significantly higher in A1 than in the CK group, but significantly lower in the A5 and C5 groups. Previous research indicates that most species of this genus have metal-reducing capabilities, so they have been used to bio-remediate toxic elements and heavy metal contamination [38]. However, because infections are rare and most often associated with a severely immunocompromised host state, it is unclear if Shewanella is a true pathogen.

Flavobacterium is a common pathogen of farmed fish [39]. It can cause acute, subacute, and chronic infections [40], which often leads to high mortality and economic losses. However, Flavobacterium also can positively effect organisms. For example, it frequently harbors extracellular macromolecular-degrading enzymes, including amylase, cellulase, chitinase, peptidases, and diverse glycoside hydrolases (GH), which enable the bacteria to digest easily degradable polymers like starch and recalcitrant biopolymers like chitin. For this reason, it has an important role in the turnover of certain organic matter (carbohydrates, amino acids, proteins, and polysaccharides) [41, 42]. In addition, Flavobacterium has shown specific detoxifying capabilities against $\mathrm{NaCl}$ toxicity to Nannochloropsis oculata growth [43]. However, the mechanisms for this effect remain unknown. In this study, the relative abundance of Flavobacterium was significantly higher in the A1, A5, and B5 groups than in the CK group. These findings suggest that the microbiota itself helps to resist pathogen invasions via competition, and gut microbiota structural changes are the consequence of competition between probiotics and pathogens.

Although there were many similarities between the control and treatment groups, there were also differences where specific genera correlated with MP levels. There were five specific genera, including Porphyromonas, Xanthobacter, Campylobacter, IMCC26134 (unclassified Verrucomicrobia), and Lachnoanaerobaculum. Most genera identified in MP treatment groups contained reported pathogens. For example, Porphyromonas is characterized as a keystone pathogen whose interactions with other bacteria are critical for the development of periodontitis [44]. Xanthobacter can grow chemolithoautotrophically and use molecular nitrogen $\left(\mathrm{N}_{2}\right)$ as its nitrogen source [45]. However, it has not been isolated from human samples to date, so the clinical significance of this genus is unknown. Campylobacter can be a pathogen for rainbow trout, with disease presentation including exophthalmia, pale liver, bloody kidney, hemorrhagic heart, and swollen intestine, but not for scattered mirror carp [46]. All of these previous findings indicate that zebrafish treated with MPs have increased risk of infection by pathogens. 
However, genera such as Lachnoanaerobaculum, isolated from the human small intestine, can produce butyrate, which provides nutrients for the tissue and protects the integrity of the intestinal mucosa [47]. Research indicates that energy deficiency in a host may correspond to a decrease in Lachnoanaerobaculum [48]. Therefore, Lachnoanaerobaculum could be considered a probiotic. The above evidence suggests that gut microbiota structural changes are the consequence of competition between probiotics and pathogens. Although MPs increase the risk of pathogen invasions, probiotics provide a potential to recover from the damage. These data provide new evidence for the hypothesis that the microbiota functions as a metabolic assistant to the host and stresses resistant entities. Additionally, as a polymer, MP cannot degrade by itself in organisms. However, as a synthetic substance, it can release toxins when accumulated in organisms over time, thus changing the structure and composition of intestinal flora and even harming organism health.

\section{Conclusions}

In summary, the effects of different sizes and different exposure times of polyethylene MPs on the gut microbiota were analyzed in zebrafish. We observed that MP treatment did not change the core microflora structure of zebrafish gut microbes, but it did change the composition and proportions of certain phyla and genera. The results obtained from this study provide new insights into the toxicity of polyethylene MP and its potential health risks to aquatic organisms. In conclusion, studies of the health risks associated with MPs are still in preliminary stages. More research is needed to determine the ecological risks of MPs, particularly with regard to the pathogenesis of MP in vivo.

\section{Acknowledgements}

This work was supported by Special Project of Agricultural Ecological Environment Protection of Ministry of Agriculture and Rural Affairs (No. 2110402), The Second National Pollution Source Survey Project (No. 2110399).

\section{Conflict of Interest}

The authors declare no conflict of interest.

\section{Reference}

1. TREMAROLI V., BACKHED F. Functional interactions between the gut microbiota and host metabolism. Nature. 489 (7415), 242, 2012.
2. ZOETENDAL E.G., AKKERMANS A.D.L., AKKERMANS-VAN VLIET W.M., DE VISSER J.A.G.M., DE VOS W.M. The host genotype affects the bacterial community in the human gastrointestinal tract. Microb. Ecol. Health Dis. 13 (3), 129, 2001.

3. YAN Q., VAN DER GAST C.J., YU Y. Bacterial community assembly and turnover within the intestines of developing Zebrafish. Plos One. 7 (1), e30603, 2012.

4. LI X.M., YU Y.H., FENG W.S., YAN Q.Y., GONG Y.C. Host species as a strong determinant of the intestinal microbiota of fish larvae. J. Microbiol. 50 (1), 29, 2012.

5. KAN H., ZHAO F., ZHANG X.X., REN H., GAO S. Correlations of gut microbial community shift with hepatic damage and growth inhibition of Carassius auratus induced by pentachlorophenol exposure. Environ. Sci. Technol. 49 (19), 11894, 2015.

6. CHEN L., GUO Y., HU C., LAM P.K.S., LAM J.C.W., ZHOU B. Dysbiosis of gut microbiota by chronic coexposure to titanium dioxide nanoparticles and bisphenol A: Implications for host health in zebrafish. Environ. Pollut. 234, 307, 2018.

7. JIN Y., WU S., ZENG Z., FU Z. Effects of environmental pollutants on gut microbiota. Environ. Pollut. 222, 1, 2017.

8. PITT J.A., KOZAL J.S., JAYASUNDARA N., MASSARSKY A., TREVISAN R., GEITNER N., WIESNER M., LEVIN E.D., DI GIULIO R.T. Uptake, tissue distribution, and toxicity of polystyrene nanoparticles in developing zebrafish (Danio rerio). Aquat. Toxicol. 194, 185, 2018.

9. ROCHMAN C.M., HOH E., KUROBE T., TEH S.J. Ingested plastic transfers hazardous chemicals to fish and induces hepatic stress. Sci. Rep. 3, 3263, 2013.

10. KIM S.W., KIM D., CHAE Y., AN Y.J. Dietary uptake, biodistribution, and depuration of microplastics in the freshwater diving beetle Cybister japonicus: Effects on predacious behavior. Environ. Pollut. 242, 839, 2018.

11. YANG H., XIONG H., MI K., XUE W., WEI W., ZHANG Y. Toxicity comparison of nano-sized and micron-sized microplastics to Goldfish Carassius auratus Larvae. J. Hazard. Mater. 388, 122058, 2020.

12. JIN Y.X., XIA J.Z., PAN Z.H., YANG J.J., WANG W.C., FU Z.W. Polystyrene microplastics induce microbiota dysbiosis and inflammation in the gut of adult zebrafish. Environ. Pollut. 235, 322, 2018.

13. RUMMEL C.D., JAHNKE A., GOROKHOVA E., KUEHNEL D., SCHMITT-JANSEN M. Impacts of biofilm formation on the fate and potential effects of microplastic in the aquatic environment. Environ. Sci. Technol. Lett. 4 (7), 258, 2017.

14. FENG LM., HE L., JIANG S.Q., CHEN J.J., ZHOU C.X., QIAN Z.J., HONG P.Z., SUN S.L., LI C.Y. Investigating the composition and distribution of microplastics surface biofilms in coral areas. Chemosphere. 252, 126565, 2020.

15. DINAN T.G., CRYAN J.F. Regulation of the stress response by the gut microbiota: Implications for psychoneuroendocrinology. Psychoneuroendocrinology. 37 (9), 1369, 2012.

16. BRUGMAN S. The zebrafish as a model to study intestinal inflammation. Dev. Comp. Immunol. 64, 82, 2016.

17. SEKIROV I., RUSSELL S.L., ANTUNES L.C.M., FINLAY B.B. Gut microbiota in health and disease. Physiol. Rev. 90 (3), 859, 2010.

18. OEHLERS S.H., FLORES M.V., OKUDA K.S., HALL C.J., CROSIER K.E., CROSIER P.S. A chemical enterocolitis model in zebrafish larvae that is dependent on 
microbiota and responsive to pharmacological agents. Dev. Dynam. 240 (1), 288, 2011.

19. ELLIS J.L., YIN C. Histological analyses of acute alcoholic liver injury in zebrafish. Jove-J. Vis. Exp. 2017 (123), 55630, 2017.

20. JIN Y., WEI L., JIANG Q., SONG X., TENG C., FAN C., LV Y., LIU Y., SHEN W., LI L., HUANG D., XIN T. Comparison of efficacy and toxicity of bevacizumab, endostar and apatinib in transgenic and human lung cancer xenograftzebrafish model. Sci. Rep. 8 (1), 15837, 2018.

21. GHANBARI M., KNEIFEL W., DOMIG K.J. A new view of the fish gut microbiome: Advances from next-generation sequencing. Aquaculture. 448, 464, 2015.

22. HORTON A.A., SVENDSEN C., WILLIAMS R., SPURGEON D., LAHIVE E. Presence and Abundance of Microplastics in Sediments of Tributaries of the River Thames, UK. Fate and Impact of Microplastics in Marine Ecosystems From the Coastline to the Open Sea, 2017, 6, 2017.

23. LAWRENCE C. New frontiers for zebrafish management. Methods Cell Biol. 135, 483, 2016.

24. SEGATA N., IZARD J., WALDRON L., GEVERS D., MIROPOLSKY L., GARRETT W.S., HUTTENHOWER C. Metagenomic biomarker discovery and explanation. Genome Biol. 12 (6), R60, 2011.

25. LEE K.W., SHIM W.J., KWON O.Y. Size-dependent effects of micro polystyrene particles in the marine copepod Tigriopus japonicus. Environ. Sci. Technol., 47 (19), 11278, 2013.

26. JEONG C.B., WON E.J., KANG H.M., LEE M.C., HWANG D.S., HWANG U.K., ZHOU B., SOUISSI S., LEE S.J., LEE J.S. Microplastic Size-Dependent Toxicity, Oxidative Stress Induction, and p-JNK and p-p38 Activation in the Monogonont Rotifer (Brachionus koreanus). Environ. Sci. Technol. 50 (16), 8849, 2016.

27. EVARISTE L., BARRET M., MOTTIER A., MOUCHET F., GAUTHIER L., PINELLI E. Gut microbiota of aquatic organisms: A key endpoint for ecotoxicological studies. Environ. Pollut. 248, 989, 2019.

28. CHOI J.S., HONG S.H., PARK J.W. Evaluation of microplastic toxicity in accordance with different sizes and exposure times in the marine copepod Tigriopus japonicus. Mar. Environ. Res. 153, 104838, 2020.

29. DAVIS D.J., DOERR H.M., GRZELAK A.K., BUSI S.B., JASAREVIC E., ERICSSON A.C., BRYDA E.C. Lactobacillus plantarum attenuates anxiety-related behavior and protects against stress-induced dysbiosis in adult zebrafish. Sci. Rep. 6, 33726, 2016.

30. HART M.L., MEYER A., JOHNSON P.J., ERICSSON A.C. Comparative Evaluation of DNA Extraction Methods from Feces of Multiple Host Species for Downstream Next-Generation Sequencing. Plos One. 10 (1), e0143334, 2015.

31. LU L., WAN Z.Q., LUO T., FU Z.W., JIN Y.X. Polystyrene microplastics induce gut microbiota dysbiosis and hepatic lipid metabolism disorder in mice. Sci. Total Environ. 631632, 449, 2018.

32. LI K., BIHAN M, METHE B.A. Analyses of the Stability and Core Taxonomic Memberships of the Human Microbiome. Plos One. 8, e63139, 2013.

33. TOTH E.M., VENGRING A., HOMONNAY Z.G., KEKI Z., SPROEER C., BORSODI A.K., MARIALIGETI K., SCHUMANN P. Phreatobacter oligotrophus gen. nov., sp nov., an alphaproteobacterium isolated from ultrapure water of the water purification system of a power plant. Int. J. Syst. Evol. Microbiol. 64, 839, 2014.
34. STANISH L.F., HULL N.M., ROBERTSON C.E., HARRIS J.K., STEVENS M.J., SPEAR J.R., PACE N.R. Factors influencing bacterial diversity and community composition in municipal drinking waters in the ohio river Basin, USA. Plos One. 11 (6), e0157966, 2016.

35. PERRIN Y., BOUCHON D., DELAFONT V., MOULIN L, HECHARD Y. Microbiome of drinking water: A full-scale spatio-temporal study to monitor water quality in the Paris distribution system. Water Res. 149, 375, 2019.

36. LI W.Y., TAN Q.W., ZHOU W., CHEN J.P., LI Y., WANG F., ZHANG J.P. Impact of substrate material and chlorine/ chloramine on the composition and function of a young biofilm microbial community as revealed by highthroughput $16 \mathrm{~S}$ rRNA sequencing. Chemosphere. 242, 125310, 2020.

37. HOLT H.M., GAHRN-HANSEN B., BRUUN B. Shewanella algae and Shewanella putrefaciens: clinical and microbiological characteristics. Clin. Microbiol. Infec. 11 (5), 347, 2005.

38. ZHONG C.F., HAN M.Z., YU S.J., YANG P.S., LI H.J, NING K. Pan-genome analyses of 24 Shewanella strains re-emphasize the diversification of their functions yet evolutionary dynamics of metal-reducing pathway. Biotechnol. Biofuels. 11, 193, 2018.

39. YE G., DONG X., YANG Q., CHI S., LIU H., ZHANG H., TAN B., ZHANG S. A formulated diet improved digestive capacity, immune function and intestinal microbiota structure of juvenile hybrid grouper (Epinephelus fuscoguttatus female $\mathrm{x}$ Epinephelus lanceolatus male) when compared with chilled trash fish. Aquaculture. 523, 735230, 2020.

40. LOCH T.P, FAISAL M. Flavobacterium spartansii sp nov., a pathogen of fishes, and emended descriptions of Flavobacterium aquidurense and Flavobacterium araucananum. Int. J. Syst. Evol. Microbiol. 64, 406, 2014.

41. BERNARDET J.F., NAKAGAWA Y. An Introduction to the Family Flavobacteriaceae. In The Prokaryotes: Volume 7: Proteobacteria: Delta, Epsilon Subclass, DWORKIN M., FALKOW S., ROSENBERG E., SCHLEIFER K.H., STACKEBRANDT E., Eds., Springer New York, New York, NY, 455, 2006.

42. BERNARDET J.F, BOWMAN J.P. The Genus Flavobacterium. In The Prokaryotes: Volume 7: Proteobacteria: Delta, Epsilon Subclass, DWORKIN M., FALKOW S., ROSENBERG E., SCHLEIFER K.H., STACKEBRANDT E., Eds., Springer New York, New York, NY, 481, 2006.

43. ODA T., KOMATSU N., MURAMATSU T., NONAKA A. SUMINTO, HIRAYAMA K. Detoxifying ability of marine bacterium Flavobacterium sp against a toxic contaminant in the reagent sodium chloride to Nannochloropsis oculata. Fisheries Sci. 66 (2), 241, 2000.

44. HAJISHENGALLIS G., LIANG S., PAYNE M.A., HASHIM A., JOTWANI R., ESKAN M.A., MCINTOSH M.L., ALSAM A., KIRKWOOD K.L., LAMBRIS J.D., DARVEAU R.P, CURTIS M.A. Low-abundance biofilm species orchestrates inflammatory periodontal disease through the commensal microbiota and complement. Cell Host Microbe. 10 (5), 497, 2011.

45. WIEGEL J. The Genus Xanthobacter. In The Prokaryotes: Volume 5: Proteobacteria: Alpha and Beta Subclasses, DWORKIN M., FALKOW S., ROSENBERG E., SCHLEIFER K.H., STACKEBRANDT E., Eds., Springer New York, New York, NY, 290, 2006.

46. AYDIN S., GULTEPE N., YILDIZ H. Natural and experimental infections of Campylobacter cryaerophila 
in rainbow trout: Gross pathology, bacteriology, clinical pathology and chemotherapy. Fish Pathol. 35, 117, 2000.

47. HEDBERG M.E., MOORE E.R.B., SVENSSONSTADLER L., HORSTEDT P., BARANOY V., HERNELL O., WAI S.N., Hammarstrom, S., Hammarstrom, M. L. Lachnoanaerobaculum gen. nov., a new genus in the Lachnospiraceae: characterization of Lachnoanaerobaculum umeaense gen. nov., sp nov., isolated from the human small intestine, and Lachnoanaerobaculum orale sp nov., isolated from saliva, and reclassification of Eubacterium saburreum (Prevot 1966) Holdeman and Moore 1970 as Lachnoanaerobaculum saburreum comb. nov. Int. J. Syst. Evol. Microbiol. 62, 2685, 2012.

48. LUO L., HU M.H., LI Y., CHEN Y.X., ZHANG S.B., CHEN J.H., WANG Y.Y., LU B.Y., XIE Z.Y., LIAO Q.F. Association between metabolic profile and microbiomic changes in rats with functional dyspepsia. RSC Adv. 8 (36), 20166, 2018. 